\title{
Atroposelective Enzymatic Synthesis of Cyclophanes
}

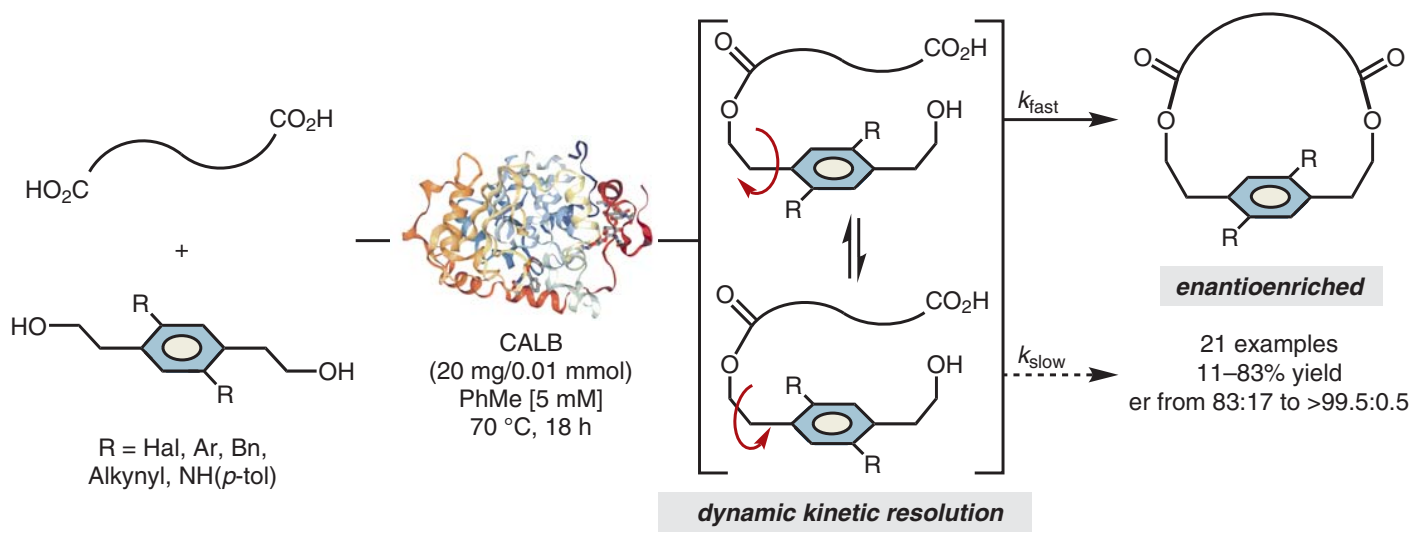

Selected examples:

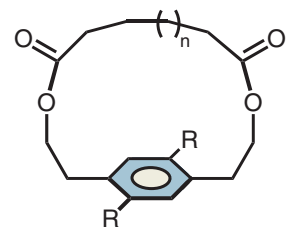

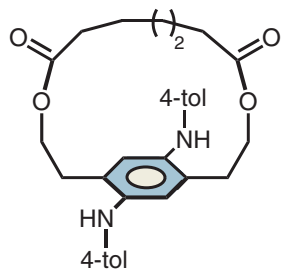

$56 \%$ yield, er $=98: 2$

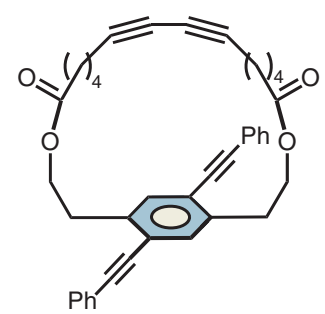

$39 \%$ yield, er $>99.5: 0.5$

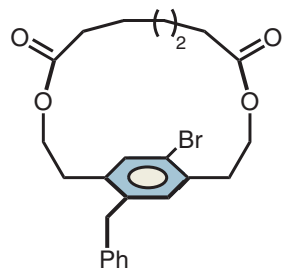

$37 \%$ yield, er $>99.5: 0.5$

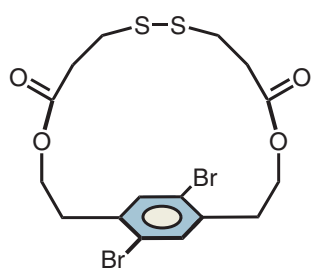

$52 \%$ yield, er $>99.5: 0.5$

$\mathrm{n}=1, \mathrm{R}=\mathrm{Br}: 68 \%$ yield, er $>$ 99.5:0.5

$\mathrm{n}=3, \mathrm{R}=\mathrm{Br}: 80 \%$ yield, er $>$ 99.5:0.5

$\mathrm{n}=4, \mathrm{R}=\mathrm{Br}: 79 \%$ yield, er $=50: 50$ !

$\mathrm{n}=4, \mathrm{R}=\mathrm{I}: \mathbf{6 3} \%$ yield, er $=\mathbf{9 8 : 2}$

derivatization via

$\mathrm{R}=\underset{\text { Bpin, styrenyl },}{\mathrm{Ar}, \text { alkynyl }}$
,

cross-couplings

Significance: The Collins group reports a lipasecatalyzed dynamic kinetic resolution process to afford enantioenriched cyclophanes from simple building blocks in moderate to good yields and excellent enantioselectivities. Although the enzyme pocket is sensitive to substitution on the central arene ring, the successful employment of aryl halides provides a synthetic handle for subsequent cross-coupling derivatization, such that motifs that might not otherwise be tolerated by the enzyme active site can be accessed.
Comment: Seemingly minute structural changes to the skeleton of a cyclophane can have unpredictable effects on the rigidity and, consequently, the conformational stability of such a molecule. Striking a balance between the maintenance of this conformational stability and the entropic costs of constructing a rigid system, while additionally translating chiral information, renders the asymmetric formation of such macrocycles incredibly challenging. The authors demonstrate the effectiveness of an enzyme in this otherwise elusive transformation in catalysis.

\section{Category}

Organo- and

Biocatalysis

Key words

macrocyclization

cyclophanes

enzymatic synthesis

lipase

dynamic kinetic

resolution

\section{Synfact is of the}

